\section{Schnellere Aufdosierung zugelassen}

R echtzeitig vor dem Therapiestart im Herbst hat das Paul-EhrlichInstitut (PEI) zugestimmt, ein weiteres Aufdosierungsschema für erwachsene Patienten mit Gräserpollenallergie in die Purethal ${ }^{\circledR}$-Fach- und -Gebrauchsinformation sowie die Zulassungsunterlagen aufzunehmen.

Erstmalig ist eine Aufdosierung in nur zwei Wochen und ohne Flaschenwechsel möglich. Schon nach drei Injektionen - mit $0,1 \mathrm{ml}$ gefolgt von $0,3 \mathrm{ml}$ und zuletzt $0,5 \mathrm{ml}-$ ist die Grundbehandlung mit Purethal ${ }^{\circledR}$ Gräser zukünftig abgeschlossen. Damit verkürzt sich die Aufdosierung mit Purethal ${ }^{\circledast}$ Gräser bei Erwachsenen gegenüber anderen zugelassenen Gräserpollen-Extrakten um bis zu 13 Wochen.

Die Zulassungserweiterung beruht auf einer kontrollierten Studie an 150 Erwachsenen mit einer Allergie gegen Gräserpollen. Deren Ergebnisse wurden Mitte Juni auf dem Kongress der European Academy of Allergy and Clinical Immunology in Istanbul, Türkei, erst- malig präsentiert. Dabei zeigte sich ein vergleichbar gutes Sicherheitsprofil für

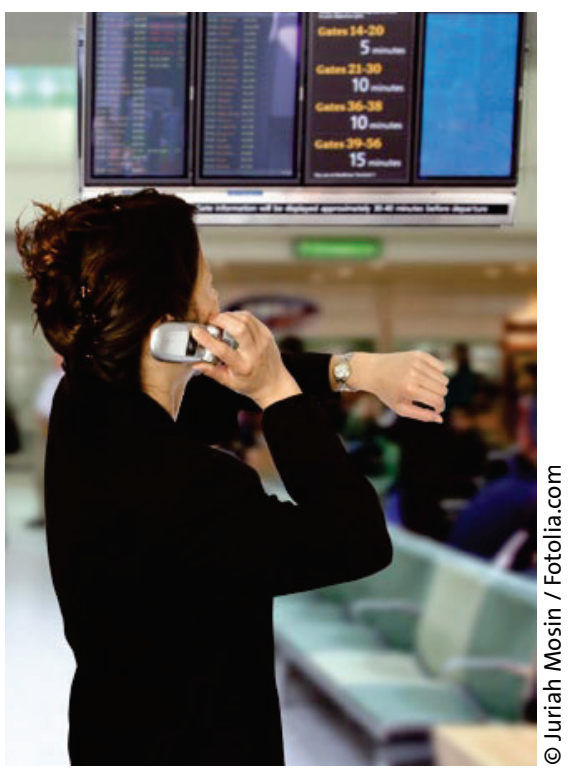

Die Grundimmunisierung mit Gräserpollen-Extrakten ist auch bei vollem Terminplan möglich: innerhalb von zwei Wochen ist sie künftig abgeschlossen. die Rush-Aufdosierung in zwei Wochen im Vergleich zur konventionellen Aufdosierung mit Purethal ${ }^{\circledR}$ Gräser in fünf Wochen. Die untersuchten immunologischen Wirksamkeitsparameter stiegen nach vier Monaten Therapie in der Rush-Gruppe gegenüber dem Ausgangswert signifikant an. Zwischen dem konventionellen und dem Rush-Aufdosierungsschema waren hierbei keine Unterschiede auszumachen.

Aktuelle Informationen zu HALProdukten werden auch beim Industriesymposium „HAL Allergie: ,High Noon - 100 Jahre Immuntherapie. Ausblick auf die Trends der Zukunft" im Rahmen des 6. Deutschen Allergiekongresses am 8. September 2011 in Wiesbaden präsentiert. Als Referenten sprechen Prof. Dr. Stefan Zielen, Frankfurt/Main, über schnelle Aufdosierung mit Allergoiden, Prof. Dr. Ludger Klimek, Wiesbaden, über die Steuerbarkeit der HochdosisSLIT und Dr. Stef Koppelmann, Leiden, Niederlande, über die Immuntherapie für Nahrungsmittelallergien.

\section{red}

Nach Informationen von HAL Allergie, Düsseldorf

Als einziges der verschreibungspflichtigen Antihistaminika blockiert Rupatadin nicht nur den H1-Rezeptor für Histamin, sondern wirkt als dualer Antagonist auch auf Rezeptoren für den plättchenaktivierenden Faktor (PAF-Rezeptoren). Der plättchenaktivierende Faktor aktiviert als starker Entzündungsmediator zahlreiche an Entzündungsreaktionen beteiligte Zellen wie Makrophagen, Neutrophile, Eosinophile, Basophile und Mastzellen und kann auch von diesen freigesetzt werden. So hemmt Rupatadin im zeitlichen Verlauf der allergischen Reaktion sowohl die allergische Sofort- als auch die Spätreaktion, wobei seine Wirkung in der Sofortphase auf seiner antihistaminergen und Anti-PAF-Aktivität und in der Spätphase vor allem auf seinen antiinflammatorischen Eigenschaften beruht.

red

Nach Informationen von Merckle-Recordati, Ulm 